\title{
A Safety Performance Assessment Framework for the Petroleum Industry's Sustainable Development Based on FAHP-FCE and Human Factors
}

\author{
Junqiao Zhang ${ }^{1}$, Xuebo Chen ${ }^{1, *}$ and Qiubai Sun ${ }^{2}$ \\ 1 School of Electronics and Information Engineering, University of Science and Technology Liaoning, \\ Anshan 114051, China \\ 2 School of Business Administration, University of Science and Technology Liaoning, Anshan 114051, China \\ * Correspondence: xuebochen@126.com; Tel.: +86-0412-5928-367
}

Received: 20 May 2019; Accepted: 25 June 2019; Published: 28 June 2019

check for updates

\begin{abstract}
Sustainability is a key factor in petroleum industry development, determining whether an enterprise has the ability to maintain high-quality safety management in the long term. In order to reduce occupational injuries and accidents, and to improve safety in the petroleum industry, this study proposes a hybrid approach based on the fuzzy analytical hierarchy process (FAHP), human factors, and the fuzzy comprehensive evaluation (FCE) method in order to assess safety performance in a petroleum enterprise. This paper is comprised of four stages. In the first stage, a model is constructed for assessing the safety of the petroleum industry based on a literature review. In the second stage, we use the FAHP to determine the weights of five factors and 19 sub-factors. In the third stage, employees are the subjects of a questionnaire on the safety performance of the petroleum enterprise. According to the analysis of the assessment results, we focus on improving employees' safety behaviors and mental health. A second round of questionnaires is distributed to the employees, and a second set of assessment results obtained. Finally, the results of the two evaluations are compared, and the effectiveness of the combination of FAHP, human factors, and FCE is verified.
\end{abstract}

Keywords: petroleum industry; sustainable development; fuzzy analytic hierarchy process (FAHP); human factors; safety communication

\section{Introduction}

Sustainability is often regarded as one of the main goals of the petroleum industry [1]. At the same time, the exploitation of oil resources is among the main causes of occupational injuries and accidents that have raised many sustainability issues [2]. The oil industry plays a core role in feeding society's demand for power, transport, and heat. However, the oil industry is considered a very dangerous sector [3], since the rate of occupational accidents and injuries is consistently high [4]. The cost of occupational accidents and injuries is extreme, not only for an employee, but also for the future life of his or her whole family [5]. Millions of occupational injuries and accidents occur around the world every year and cause negative impacts on employees, enterprise, society, and national economies. The task of oil accident prevention appears enormous but understanding and identifying the root causes of these accidents and occupational injuries will help us to implement better safety management to prevent their re-occurrence.

The oil refinery industry has experienced a series of disastrous accidents, and statistics show that most of these accidents are caused by human factors [6,7]. For example, the BP Texas City oil refinery explosion in 2005 resulted in about 15 fatalities [8] and the Piper Alpha offshore oil industry accident in 1988 led to 167 deaths and dozens of serious injuries [9]. These have all been investigated 
and the importance of human factors in the causation of occupational injuries and accidents is well established. Furthermore, the role of human factors involving hazardous technology failures is increasingly recognized by both organizational [10] and technical specialists [11], such as in the Piper Alpha disaster. Pate-Cornell [12] attributed the accident to poor maintenance procedures, inexperience, and a lack of learning mechanisms. However, compared to in other industries such as sewage treatment plants and nuclear power plants, the key role of human factors in the oil industry has not been fully researched. This may be partly due to a lack of routinization of petroleum operations and the oil industry being more widely distributed geographically than other industries. Urbina [13] points out that the activities of the oil industry tend to be loosely regulated and that enterprises and individuals often operate independently. Previous studies have shown that human error and unsafe acts play an important role in the occurrence of oil accidents. In fact, engineers have long pointed out that the psychological and emotional health of employees plays a central role in human performance [14]. Decreased concentration, distractibility, and a tendency to emotional exhaustion and cognitive failure increase the probability of human error and procedural violations. This includes the influence of an employee's physical or psychological fatigue and the likelihood of distraction by personal concerns, such as marital discord or personal or family illness. In addition, reduced levels of physical health and psychological well-being may directly or indirectly influence the incidence of occupational injuries and accidents. To reduce the possibility of oil industry accidents, this study focused on the behavioral and psychological health of the employees, following a bottom-up approach which starts from the understanding and identification of potential unsafe behavior in order to assess employees' well-being [15]. Thus, one effective approach used to combat unsafe human action is behavior-based safety (BBS) [16]. BBS is deemed to be an effective approach to further prevent oil industry accidents. BBS has been successfully applied in a wide range of areas such as health care and hospitals [17,18], transportation [19-21], manufacturing [22], and construction [23-25]. These successful applications illustrated the effectiveness of the BBS approach for identifying potentially risky or unsafe behaviors [26].

In this context, bottom-up safety communication is also conducive to improving the safety performance of the oil industry and the safety behaviors of employees [27]. Over the past few decades, a decline in oil refinery accidents has been associated with improvements in safety communication. For example, in 2003, after management became more involved in safety communication, the accident rate began to fall below the industry averages published by the National Petroleum Refiners Association and the Bureau of Labor Statistics, and continued to decline in 2007. The Cambridge Center for Behavioral Studies (CCBS) has also published data indicating that there is an inverse relationship between the number of safety communications made by oil refinery employees and the accident rate [28]. In this study, the effectiveness of safety communication in Chinese state-owned oil enterprises may be correlated to organizational power distance. Power distance refers to the extent to which individuals accept the unequal distribution of power in institutions and organizations and consider it a normal phenomenon [14]. Low power distance means that there is a closer relationship between the leader and the employees, since the organizational and administrative structure is flatter and employees are more involved in safety communication [29]. However, a high-power distance may lead to a one-way flow of communication from leaders to employees, which prevents the knowledge and experience of employees from being used to improve safety communication in a bottom-up manner.

Despite the qualitative nature of the method, it can be used to better understand employees' perception of unsafe behaviors and their psychology, and provides practical evidence to assess and improve their safety behaviors. Hence, these first results can improve safety performance in the oil industry, providing a basis for further analysis and assessment of safety behaviors and psychology related to employees, which are considered core factors in the prevention of occupational injury and accidents [15]. Moreover, the interdisciplinary part of the human factor means that different professionals should participate in the decision-making process, which makes the decision-making more difficult and sometimes time-consuming. The analytic hierarchy process (AHP) is a common 
method to solve interdisciplinary and multiple-criteria decision-making (MCDM) problems [30]—it was established by Saaty in the late 1970s [31,32]. So far, AHP has been widely used to assess various industries' problems, and has also been widely applied in research on occupational safety issues [33,34]. In particular, the determinants of safety behavior and psychological well-being include intangible aspects and require accurate data [35]. Furthermore, it is increasingly difficult to describe and assess an enterprise's safety performance. Since human judgments are usually uncertain, there is no accurate numerical value to assess their preferences. Since decision-making is done by people, ambiguity must be considered in MCDM.

However, AHP does not take inherent uncertainty and imprecision into account [36], so the comparison matrices used by AHP are combined with the crisp scale. Fuzzy set theory is a reasonable and effective tool to solve the problem of inherent uncertainty and ambiguity. An extension of AHP, the fuzzy analytic hierarchy process (FAHP) has the ability to deal with a fuzzy multi-criteria decision-making problem. This method has been applied by numerous scholars to deal with different decision-making problems. In order to handle the inherent uncertainty or fuzziness of data (to assess the psychological behavior of employees, etc.), the FAHP has been successfully applied in many fields in recent years, such as in-flight service quality [37], energy investments [38,39], transportation engineering management [40,41], application in the army [42], project prioritization and selection [43], and healthcare service quality [44]. Furthermore, fuzzy AHP is also applied in combination with other methods to tackle actual making-decision and management problems $[45,46]$. Therefore, it is necessary to apply a combination of qualitative and quantitative approaches to assess the safety performance, in which linguistic variables are involved. Then, bottom-up safety communication and BBS management are used to improve the safety behavior and mental health of the employees. Different FAHP methods have been developed by many authors, but each method has its own advantages, disadvantages, and range of application. Until now, the answer as to which is better has remained an open question [47]. In this study, AHP and triangular fuzzy numbers are applied, as well as the FAHP method developed by Buckley [48]. Thus, in this study, in order to improve an enterprise's safety performance, a novel assessment model is developed based on FAHP, human factors, and the fuzzy comprehensive evaluation (FCE) method.

The remainder of this article is organized as follows. Section 2 introduces the FAHP, AHP and FCE methods. Section 3 illustrates the application of the method to Chinese petrochemical enterprises and reports the results. Analysis and discussion of the results are provided in Section 5. Finally, the conclusions, limitations and future research are presented in Sections 6 and 7.

\section{Research Methods}

\subsection{The Weights of All the Factors and Sub-Factors}

In this study, a FAHP and original AHP are employed to calculate and compare the weight set in a petrochemical enterprise, respectively. The AHP is a structured, traditional approach for analyzing and solving multi-criteria problems based on psychology and mathematics [32]. It has been widely applied in many petroleum enterprises for sustainable safety assessment. An extension of AHP, FAHP, has the ability to deal with fuzzy MCDM problems. This method has been generally applied by integrating numerous expert opinions to improve the AHP's decision-making [49].

\subsection{Calculation of the Factors' and Sub-Factors' Weights Using FAHP}

Firstly, the geometric mean was applied to represent the interviewer's opinion consensus [32,50]. Secondly, a triangular fuzzy number (TFN) characterized by a minimum value, to measure the maximum value of the score and geometric mean, is applied to integrate $n$ pairwise comparison matrices into a fuzzy positive reciprocal matrix [49]. Finally, based on the above matrix, the FAHP is utilized to determine the weight of factors and sub-factors in a petrochemical enterprise. 
2.2.1. The Fuzzy Positive Reciprocal Matrix

Assume $\widetilde{\mathrm{A}}=\left(\widetilde{a}_{i j}\right)_{n \times n}$ is a fuzzy positive reciprocal matrix, where $\widetilde{a}_{i j}=\left(l_{i j}, m_{i j}, u_{i j}\right)$ is a TFN where

$$
\left[l_{i j}, m_{i j}, u_{i j}\right]= \begin{cases}{[1,1,1],} & \text { if } i=j \\ \frac{1}{u_{i j}}, \frac{1}{m_{i j}}, \frac{1}{l_{i j}}, & \text { if } i \neq j .\end{cases}
$$

For ease of explanation, let $A^{(k)}=\left[a_{i j}^{(k)}\right]_{n \times n^{\prime}}, k=1,2, \ldots, m$, represent the pairwise comparison matrix of $m$ interviewers. Then, these pairwise comparison matrices are integrated into the fuzzy positive reciprocal matrix as follows:

$$
\widetilde{\mathrm{A}}=\left(\widetilde{a}_{i j}\right)_{n \times n^{\prime}}
$$

where $\widetilde{a}_{i j}=\left[\min _{1 \leq k \leq 12}\left\{a_{i j}^{(k)}\right\},\left(\prod_{k=1}^{12} a_{i j}^{(k)}\right)^{\frac{1}{12}}, \max _{1 \leq k \leq 12}\left\{a_{i j}^{(k)}\right\}\right](i=1,2, \ldots, n, j=1,2, \ldots, n$ and $k=1,2$, $\ldots, m)$ is a TFN.

Based on the arithmetic operation rules for fuzzy numbers [49], the fuzzy positive reciprocal matrix $\widetilde{\mathrm{A}}=\left(\widetilde{a}_{i j}\right)_{n \times n^{\prime}}$ can be described as follows:

$$
\widetilde{a}_{i j}=\left\{\begin{array}{l}
{[1,1,1], \text { if } i=j} \\
\left(\widetilde{a}_{i j}\right)^{-1}, \text { if } i \neq j
\end{array}\right.
$$

\subsubsection{Consistency Tests of FAHP}

In order to obtain objective and reasonable expert decision results, the consistency of a fuzzy positive reciprocal matrix must be tested. Thus, a fuzzy positive reciprocal matrix needs to be converted into a crisp matrix. There are many defuzzification methods for obtaining a crisp number from a TFN [51].

In this study, Buckley's method is applied to defuzzify a fuzzy number. In this method, the geometric mean operations are used to defuzzify a fuzzy number, and this operation can convert the fuzzy positive reciprocal matrix into a crisp matrix. Then the traditional AHP is used to test the consistency of a crisp matrix. As a result, the fuzzy numbers $\widetilde{a}_{i j}=\left(l_{i j}, m_{i j}, u_{i j}\right)$ in the $\widetilde{A}$ can be defuzzified as follows:

$$
\widetilde{a}_{i j}=\left(l_{i j}, m_{i j}, m_{i j}, u_{i j}\right)^{\frac{1}{4}}, i=1,2, \ldots, n, j=1,2, \ldots, n
$$

In order to test the consistency of a positive reciprocal matrix, the consistency index $(C I)$ and consistency ratio $(C R)$ are introduced and computed; they are defined as follows [32]:

$$
\begin{gathered}
\mathrm{CI}=\frac{\lambda_{\max }-n}{n-1} \\
\mathrm{CR}=\frac{C I}{R I},
\end{gathered}
$$

where $\lambda_{\max }$ is the maximum eigenvalue of the matrix, $n$ is the dimension of the matrix, and RI represents a random index, shown in Table 1 . Saaty proposed that $C I \leq 0.1$ and $C R \leq 0.1$ are acceptable ranges.

Table 1. The random consistency index.

\begin{tabular}{cccccccccc}
\hline $\boldsymbol{N}$ & $\mathbf{1}$ & $\mathbf{2}$ & $\mathbf{3}$ & $\mathbf{4}$ & $\mathbf{5}$ & $\mathbf{6}$ & $\mathbf{7}$ & $\mathbf{8}$ & $\mathbf{9}$ \\
\hline$R I$ & 0 & 0 & 0.58 & 0.09 & 1.12 & 1.24 & 1.32 & 1.41 & 1.45 \\
\hline
\end{tabular}

If $C R>0.1$, the experts need to modify their decision. This step should be repeated until all experts' decisions are consistent. 
2.2.3. The Local Weights of All the Factors and Sub-Factors

Based on the special structure of the positive reciprocal matrix A, we applied the Normalization of the geometric mean of the rows (NGMR) method to calculate the local weights [32]. According to the arithmetic operations of fuzzy numbers [52], the geometric means of the TFNs for the $i$ th factors can be given as follows:

$$
\widetilde{\mathrm{g}}_{i}=\left(\prod_{j=1}^{n} \widetilde{a}_{i j}\right)^{\frac{1}{n}}=\left[\left(\prod_{j=1}^{n} l_{i j}\right)^{\frac{1}{n}},\left(\prod_{j=1}^{n} m_{i j}\right)^{\frac{1}{n}},\left(\prod_{j=1}^{n} u_{i j}\right)^{\frac{1}{n}}\right], i=1,2, \ldots, n .
$$

According to Equation (5), we have:

$$
\sum_{i=1}^{n} \widetilde{\mathrm{g}}_{i}=\left[\sum_{i=1}^{n}\left(\prod_{j=1}^{n} l_{i j}\right)^{\frac{1}{n}}, \sum_{i=1}^{n}\left(\prod_{j=1}^{n} m_{i j}\right)^{\frac{1}{n}}, \sum_{i=1}^{n}\left(\prod_{j=1}^{n} u_{i j}\right)^{\frac{1}{n}}\right], i=1,2, \ldots, n .
$$

The fuzzy weight of the $i$ th factors $(i=1,2, \ldots, n)$ can be expressed as follows:

$$
\widetilde{w}_{i}=\frac{\widetilde{\mathrm{g}}_{i}}{\sum_{i=1}^{n} \widetilde{\mathrm{g}}_{i}}=\left[\left(\frac{\left(\prod_{j=1}^{n} l_{i j}\right)^{\frac{1}{n}}}{\sum_{i=1}^{n}\left(\prod_{j=1}^{n} u_{i j}\right)^{\frac{1}{n}}}\right),\left(\frac{\left(\prod_{j=1}^{n} m_{i j}\right)^{\frac{1}{n}}}{\sum_{i=1}^{n}\left(\prod_{j=1}^{n} m_{i j}\right)^{\frac{1}{n}}}\right),\left(\frac{\left(\prod_{j=1}^{n} u_{i j}\right)^{\frac{1}{n}}}{\sum_{i=1}^{n}\left(\prod_{j=1}^{n} l_{i j}\right)^{\frac{1}{n}}}\right)\right], i=1,2, \ldots, n .
$$

\subsubsection{The Defuzzification Process}

Since the local weight $W_{i}$ of the $i$ th $S A(i=1,2, \ldots, n)$ is fuzzy, this study applied Yager's index to defuzzify it and convert a fuzzy number $\widetilde{w}_{i}$ into a crisp number $W_{i},(i=1,2, \ldots, n)$ [53]. Let $\widetilde{w}_{i}=\left[l_{i}^{w}, m_{i}^{w}, u_{i}^{w}\right]$, where

$$
\left[l_{i}^{w}, m_{i}^{w}, u_{i}^{w}\right]=\left[\left(\frac{\left(\prod_{j=1}^{n} l_{i j}\right)^{\frac{1}{n}}}{\sum_{i=1}^{n}\left(\prod_{j=1}^{n} u_{i j}\right)^{\frac{1}{n}}}\right),\left(\frac{\left(\prod_{j=1}^{n} m_{i j}\right)^{\frac{1}{n}}}{\sum_{i=1}^{n}\left(\prod_{j=1}^{n} m_{i j}\right)^{\frac{1}{n}}}\right),\left(\frac{\left(\prod_{j=1}^{n} u_{i j}\right)^{\frac{1}{n}}}{\sum_{i=1}^{n}\left(\prod_{j=1}^{n} l_{i j}\right)^{\frac{1}{n}}}\right)\right], i=1,2, \ldots, n .
$$

The Yager's index for the $\widetilde{w}_{i}$ can be defined as follows [53]:

$$
w_{i}=\frac{l_{i}^{w}+2 m_{i}^{w}+u_{i}^{w}}{4}, i=1,2, \ldots, n .
$$

Via normalization of $w_{i}$, the normalized local weight of the $i$ th factors can be expressed as follows:

$$
\omega_{i}=\frac{w_{i}}{\sum_{i=1}^{n} w_{i}}, i=1,2, \ldots, n
$$

\subsection{Calculation of the Factors and Sub-Factors Weights Using Original AHP}

AHP is a structured, traditional technique for integrating and analyzing multiple expert opinions. Hence, in this study, original AHP is applied for the calculation of the weight values and the integration of group decisions. 


\subsubsection{Establishment of Judgment Matrices}

The relative importance of the factors is scored by experts, and the scored results are used to construct a judgment matrix of the factors and sub-factors. To this end, Saaty's method is employed for pairwise comparisons, divided into 1-9 [32]. Thus, a reasonable judgment matrix $C$ is established:

$$
C=\left(a_{i j}\right)_{n \times n}=\left[\begin{array}{cccc}
a_{11} & a_{12} & \cdots & a_{1 n} \\
a_{21} & a_{22} & \cdots & a_{2 n} \\
\cdots & \cdots & \cdots & \cdots \\
a_{n 1} & a_{n 2} & \cdots & a_{n n}
\end{array}\right]
$$

where $a_{i j}(i, j=1,2, \ldots, n)$ is the importance pairwise comparison result of the $i$ th and $j$ th factors, and $n$ is the number of factors. The judgment matrix $C$ satisfies $a_{i j}>0, a_{j i}=1 / a_{i j}$, and $a_{i i}=1$.

\subsubsection{Weight Calculation and Consistency Check}

(1) Each row of the judgment matrix can be normalized:

$$
b_{i j}=\frac{a_{i j}}{\sum_{i=1}^{n} a_{i j}}(i, j=1,2, \ldots, n) .
$$

(2) Each column of the normalized judgment matrix is summed:

$$
w_{i}=\sum_{j=1}^{i} b_{i j} .
$$

(3) The weight vector $W=\left(W_{1}, W_{2}, \ldots, W_{n}\right)$ is normalized:

$$
\widetilde{w}_{i}=\frac{W_{i j}}{\sum_{i=1}^{n} W_{i}}
$$

(4) The maximum eigenvalues of the judgment matrix are calculated:

$$
\lambda_{\max }=\sum_{i=1}^{n} \frac{(A W)_{i}}{n W_{i}}
$$

\subsubsection{Consistency Tests of AHP}

In order to test the consistency of a judgment matrix, the consistency index $(C I)$ and consistency ratio $(C R)$ are introduced and computed; they are defined as above Equations (5) and (6).

The same principle as Section 2.2.2, Saaty proposed that $C I \leq 0.1$ and $C R \leq 0.1$ are acceptable ranges. If $C R>0.1$, the experts need to modify their decision. This step should be repeated until all experts' decisions are consistent.

\subsection{Fuzzy Comprehensive Evaluation}

\subsubsection{Evaluation Factor Set}

$$
U=\left\{U_{1}, U_{2}, \ldots, U_{m}\right\}
$$

The factors $U_{i}(i=1,2, \ldots, m)$ denote different influencing factors of the assessment object. 


\subsubsection{Evaluation Result Set}

The evaluation factor set is composed of the different evaluation results of the assessment object, which is generally described by fuzzy language. The evaluation result set can be expressed as follows:

$$
V=\left\{V_{1}, V_{2}, \ldots, V_{n}\right\}
$$

In this study, the evaluation result can be divided into five classifications, as follows $(n=5): V_{1}$ : very high, $V_{2}$ : high, $V_{3}$ : average, $V_{4}$ : low, $V_{5}$ : very low.

\subsubsection{Fuzzy Relation Matrix R}

Firstly, the single factor evaluation is to be established as below:

Assume an evaluation result set $V=\left\{V_{1}, V_{2}, \ldots, V_{5}\right\}$ and its corresponding scores are as shown in Table 2.

Table 2. Evaluation set and its corresponding scores.

\begin{tabular}{cccccc}
\hline Grade & Very High & High & Average & Low & Very Low \\
\hline score & $P_{5}$ & $P_{4}$ & $P_{3}$ & $P_{2}$ & $P_{1}$ \\
value & 5 & 4 & 3 & 2 & 1 \\
\hline
\end{tabular}

Suppose there are $N$ participants in the questionnaire sample $X$ and the participant number set corresponding to each rating level is $N_{i j}=\left(N_{i j 1}, N_{i j 2}, N_{i j 3}, N_{i j 4}, N_{i j 5}\right), \sum_{k=1}^{5} N_{i j k}=N$, then the single-factor evaluation from $u_{i j}$ to the evaluation result set $V$ is shown as follows:

$$
\begin{gathered}
R_{i j}=\left(r_{i j 1}, r_{i j 2}, r_{i j 3}, r_{i j 4}, r_{i j 5}\right) \\
r_{i j k}=\frac{p_{k} \cdot N_{i j k}}{\sum_{k=1}^{5} p_{k} \cdot N_{i j k}}, i=1,2, \ldots, 5, j=1,2, \ldots, n_{i}
\end{gathered}
$$

where $\sum_{k=1}^{5} r_{i j k}=1$. Then, the fuzzy relation matrix is to be established. According to the single-factor evaluation established in the previous step, the fuzzy relation matrix can be expressed as below:

$$
R=\left[\begin{array}{cccc}
r_{11} & r_{12} & \cdots & r_{1 n} \\
r_{21} & r_{22} & \cdots & r_{2 n} \\
\vdots & \vdots & \vdots & \vdots \\
r_{m 1} & r_{m 2} & \cdots & r_{m n}
\end{array}\right]
$$

where $R$ represents the fuzzy relationship between the factor set $U$ and evaluation result set $V$.

\subsubsection{Fuzzy Comprehensive Evaluation}

The FAHP is applied to determine the weight values $W$. Thus, the fuzzy relation matrix $R$ can be used to construct the FCE model:

$$
B=W \cdot R=\left(a_{1}, a_{2}, \ldots, a_{m}\right)\left[\begin{array}{cccc}
r_{11} & r_{12} & \cdots & r_{1 n} \\
r_{21} & r_{22} & \cdots & r_{2 n} \\
\vdots & \vdots & \vdots & \vdots \\
r_{m 1} & r_{m 2} & \cdots & r_{m n}
\end{array}\right]=\left(b_{1}, b_{2}, \ldots, b_{n}\right)
$$

The FCE results can be calculated by multiplying the weight set $W$ and the fuzzy relation matrix $R$. After normalization, the calculated standard evaluation result is $B$. 


\section{A Petrochemical Enterprise Application}

\subsection{The Weights of Factors and Sub-Factors}

Due to a growing awareness of the increasing importance of BBS, the Chinese petroleum industry has applied more BBS practices to their management processes, which creates some benefits for the enterprises. Thus, to better understand BBS practices in the Chinese petrochemical industry, this paper selected a well-known petroleum enterprise in the east of China as an empirical study. This petroleum enterprise includes an administrative service division, oil production crew, geological team, oil and gas gathering team, and hydropower team.

\subsection{Questionnaire Design}

This study, based on the literature on BBS [54-58], safety climate, and process safety, considers industrial characteristics of the petroleum industry and organizes items to interview employees about their attitudes to safety. The survey and interview results provide a reasonable scientific reference for questionnaire design. However, different groups may have various perceptions of safety attitudes. Perceptions of the behaviors and attitudes of senior managers are associated with the safety operation behaviors of employees [59]. The opinions and behavior of top management influence employees' views about safety policies. Top and middle management may have a limited understanding of the safety attitudes of grass-roots employees [60]. Furthermore, there may be different perceptions between horizontal departments. The hierarchy of the case study consists of five factors and 19 sub-factors, as shown in Figure 1.

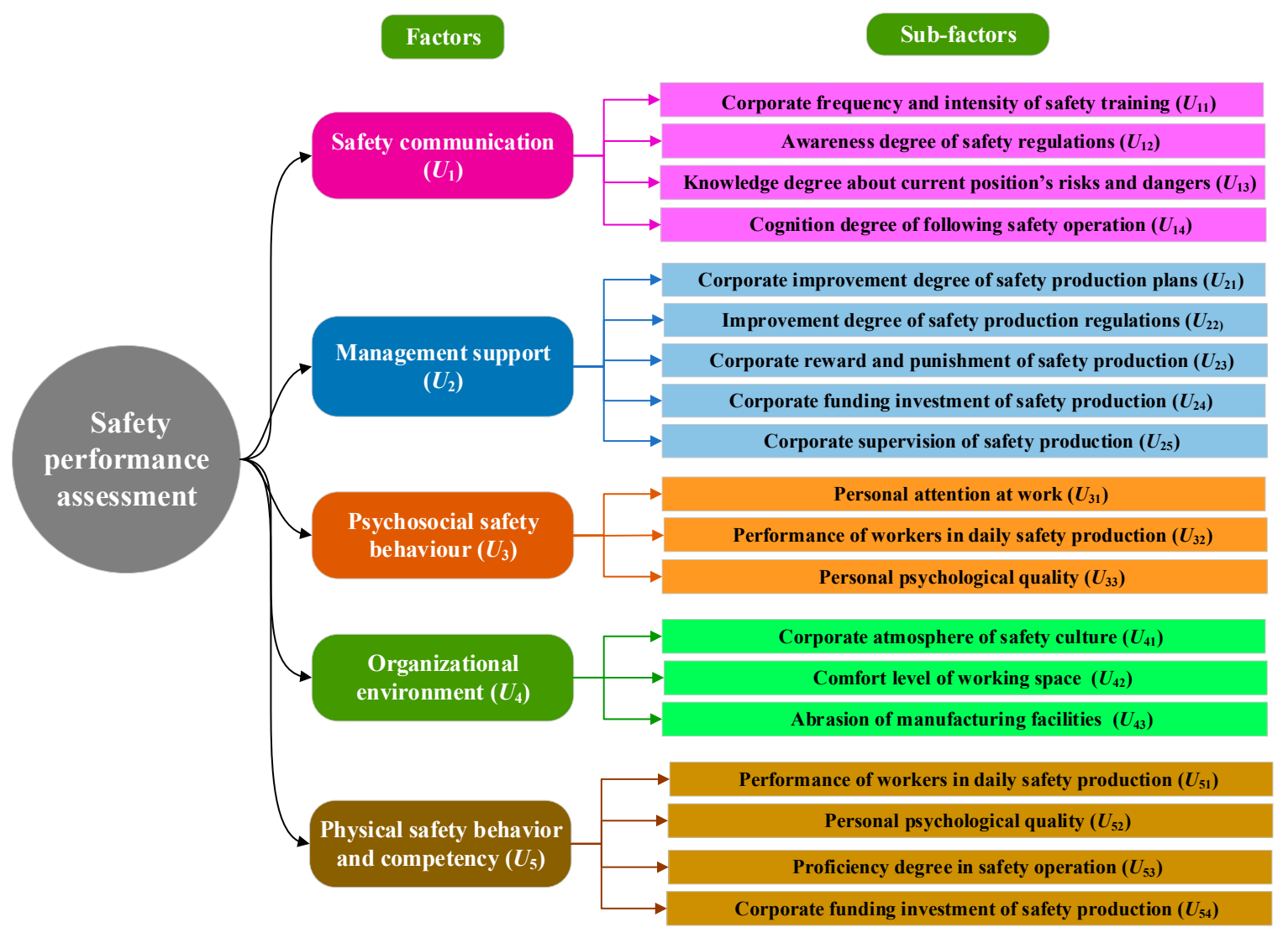

Figure 1. The hierarchy framework of safety performance assessment. 


\subsection{Calculating the Weight of the Factors Using FAHP}

In order to calculate the factor and sub-factor weights, the senior and middle management of the petrochemical enterprise were surveyed. In this study, an AHP questionnaire with a nine-point rating scale is designed to measure their preference for each factor. Furthermore, with the help of an experienced researcher, 12 groups of 36 experienced senior and middle managers, scholars, and employees in China have also been interviewed and answered the AHP questionnaire. In the next stage, the manager, experts, and scholars, based on their experiences, used pairwise criteria to weight the factors and sub-factors. To enhance the validity of the questionnaire, this study employed an interview survey rather than a questionnaire to fill in.

\subsubsection{The Local Weights of All the Factors Using FAHP}

After that, the local weights of all the factors and sub-factors were obtained based on the method proposed in Section 2.2. Taking the first-layer data as an example, based on Equation (2), the fuzzy positive reciprocal matrix A was obtained as follows:

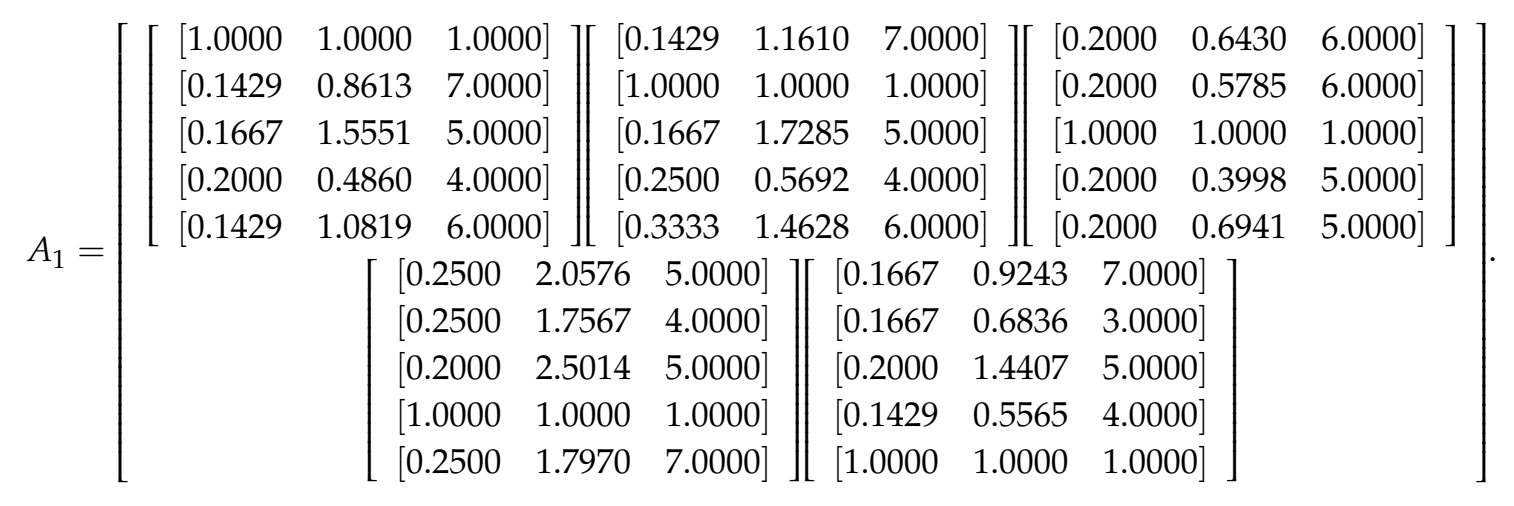

According to Equation (4), the $\widetilde{A_{1}}$ can be defuzzified as follows:

$$
A_{1}=\left[\begin{array}{lllll}
1.0000 & 1.0776 & 0.8393 & 1.5167 & 0.9992 \\
0.9281 & 1.0000 & 0.7961 & 1.3254 & 0.6953 \\
1.1915 & 1.2562 & 1.0000 & 1.5816 & 1.2003 \\
0.6593 & 0.7545 & 0.6323 & 1.0000 & 0.6486 \\
1.0009 & 1.4383 & 0.8331 & 1.5418 & 1.0000
\end{array}\right] .
$$

By using Equations (5) and (6), $C I=0.0028, C R=0.0025<0.1$. This shows that A has satisfactory consistency. Then, the $C R$ values for all the positive reciprocal matrixes of the sub-factors can be obtained (the operation method is the same as that applied in Table 1). Finally, due to all of the $C R$ values being confirmed to be less than $10 \%$, the consistency in each positive reciprocal can be accepted.

In the example of $A$, the geometric mean of triangular fuzzy numbers $\widetilde{g}_{i}(i=1,2, \ldots, 5)$ is obtained via Equation (7):

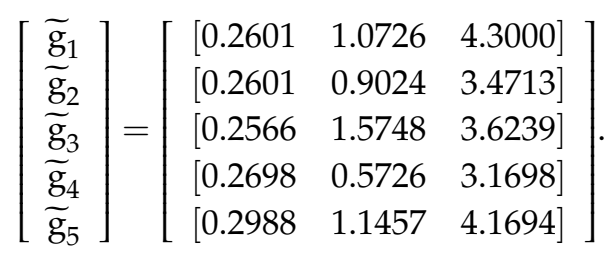

From Equation (8), we have

$$
\sum_{i=1}^{5} \widetilde{\mathrm{g}}_{i}=[1.3454,5.2682,18.7343] .
$$


Then, the $\widetilde{\mathrm{w}}_{i}$ for the $i$ th factor $(i=1,2, \ldots, n)$ can be obtained via Equation (9):

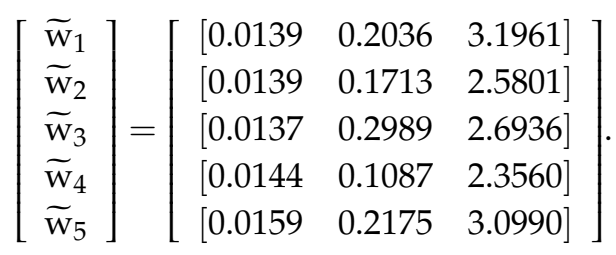

\subsubsection{The Defuzzification Process}

In the example of $A, w_{i}$ and $\omega_{i}(i=1,2, \ldots, 5)$ can be calculated by Equations (11) and (12):

$$
\left[\begin{array}{l}
\mathrm{w}_{1} \\
\mathrm{w}_{2} \\
\mathrm{w}_{3} \\
\mathrm{w}_{4} \\
\mathrm{w}_{5}
\end{array}\right]=\left[\begin{array}{l}
0.7234 \\
0.5873 \\
0.6610 \\
0.5176 \\
0.7100
\end{array}\right] \Longrightarrow\left[\begin{array}{l}
\omega_{1} \\
\omega_{2} \\
\omega_{3} \\
\omega_{4} \\
\omega_{5}
\end{array}\right]=\left[\begin{array}{l}
0.2216 \\
0.1836 \\
0.2066 \\
0.1618 \\
0.2219
\end{array}\right] .
$$

where $\omega_{i}(i=1,2, \ldots, 5)$ are the weights of the factors.

Similarly, using the same method, the weights of the sub-factors can also be obtained as in Table 3.

\begin{tabular}{|c|c|c|c|}
\hline Factors and Sub-Factors & Local Weight & Global Weight & Rank \\
\hline Safety communication $U_{1} / C_{1}$ & $0.2261 / 0.3479$ & & \\
\hline Corporate frequency and intensity of safety training $U_{11} / C_{11}$ & $0.2248 / 0.1334$ & $0.0508 / 0.0464$ & $12 / 6$ \\
\hline Awareness degree of safety regulations $U_{12} / C_{12}$ & $0.2729 / 0.4208$ & $0.0617 / 0.1464$ & $6 / 2$ \\
\hline Knowledge degree about current position's risks and dangers $U_{13} / C_{13}$ & $0.2768 / 0.3295$ & $0.0626 / 0.1146$ & $5 / 4$ \\
\hline Cognition degree of following safety operation $U_{14} / C_{14}$ & $0.2255 / 0.1163$ & $0.0510 / 0.0405$ & $11 / 8$ \\
\hline Management support $U_{2} / C_{2}$ & $0.1836 / 0.0733$ & & \\
\hline Corporate improvement degree of safety production plans $U_{21} / C_{21}$ & $0.2130 / 0.1597$ & $0.0391 / 0.0117$ & $16 / 15$ \\
\hline Improvement degree of safety production regulations $U_{22} / C_{22}$ & $0.2323 / 0.1315$ & $0.0427 / 0.0096$ & $15 / 16$ \\
\hline Corporate reward and punishment of safety production $U_{23} / C_{23}$ & $0.1699 / 0.0756$ & $0.0312 / 0.0055$ & $19 / 18$ \\
\hline Corporate funding investment of safety production $U_{24} / C_{24}$ & $0.1983 / 0.2424$ & $0.0364 / 0.0178$ & $17 / 13$ \\
\hline Corporate supervision of safety production $U_{25} / C_{25}$ & $0.1866 / 0.3908$ & $0.0343 / 0.0286$ & $18 / 11$ \\
\hline Psychosocial safety behavior $U_{3} / C_{3}$ & $0.2066 / 0.3368$ & & \\
\hline Personal attention at work $U_{31} / C_{31}$ & $0.3761 / 0.1047$ & $0.0777 / 0.0353$ & $1 / 9$ \\
\hline Performance of workers in daily safety production $U_{32} / C_{32}$ & $0.3084 / 0.6370$ & $0.0637 / 0.2145$ & $4 / 1$ \\
\hline Personal psychological quality $U_{33} / C_{33}$ & $0.3154 / 0.2583$ & $0.0652 / 0.0870$ & $3 / 5$ \\
\hline Organizational environment $U_{4} / C_{4}$ & $0.1618 / 0.1875$ & & \\
\hline Corporate atmosphere of safety culture $U_{41} / C_{41}$ & $0.3350 / 0.2430$ & $0.0542 / 0.0456$ & $8 / 7$ \\
\hline Comfort level of working space $U_{42} / C_{42}$ & $0.3029 / 0.6255$ & $0.0490 / 0.1173$ & $13 / 3$ \\
\hline Abrasion of manufacturing facilities $U_{43} / C_{43}$ & $0.3622 / 0.1315$ & $0.0586 / 0.0247$ & $7 / 12$ \\
\hline Physical safety behavior and competency $U_{5} / C_{5}$ & $0.2219 / 0.0545$ & & \\
\hline Personal physical health $U_{51} / C_{51}$ & $0.2341 / 0.0580$ & $0.0519 / 0.0032$ & 9/19 \\
\hline Fatigue degree at work $U_{52} / C_{52}$ & $0.2316 / 0.5262$ & $0.0514 / 0.0287$ & $10 / 10$ \\
\hline Proficiency degree in safety operation $U_{53} / C_{53}$ & $0.2207 / 0.1308$ & $0.0490 / 0.0071$ & $14 / 17$ \\
\hline Corporate funding investment of safety production $U_{54} / C_{54}$ & $0.3135 / 0.2851$ & $0.0696 / 0.0155$ & $2 / 14$ \\
\hline
\end{tabular}

Table 3. Global weights for sub-factors.

\subsubsection{Calculation of the Global Weights of Sub-Factors}

The global weights of sub-factors can be obtained by multiplying the local weights of the sub-factor by the weights of the factor to which they belong. The results are shown in Table 3.

\subsection{Calculating the Weight of the Factors Using AHP}

\subsubsection{The Local Weights of All the Factors Using AHP}

In Section 3.3, an AHP questionnaire is designed to measure the preference for each factor. Twelve groups of 36 experienced senior and middle managers, scholars, and employees have been interviewed 
and answered the AHP questionnaire. In this study, we employed an interview survey rather than a fill-in questionnaire.

$$
C=\left[\begin{array}{ccccc}
1 & 7 & 0.5 & 3 & 5 \\
0.1429 & 1 & 0.2 & 0.5 & 2 \\
2 & 5 & 1 & 1 & 4 \\
0.3333 & 2 & 1 & 1 & 4 \\
0.2 & 0.5 & 0.25 & 0.25 & 1
\end{array}\right]
$$

According to Equations (13)-(16), the weights $C_{i}(i=1,2, \ldots, 5)$ can be calculated as follows:

$$
\left[\begin{array}{l}
C_{1} \\
C_{2} \\
C_{3} \\
C_{4} \\
C_{5}
\end{array}\right]=\left[\begin{array}{l}
0.3479 \\
0.0733 \\
0.3368 \\
0.1875 \\
0.0545
\end{array}\right]
$$

$C R=0.0801<0.1$ is calculated using Equations (5)-(6). The weight distribution of the comparison matrix is reasonable, and has satisfactory consistency.

Similarly, using the same method, the weights of the sub-factors can also be obtained as in Table 3 .

\subsubsection{Calculation of the Global Weights of Sub-Factors Using AHP}

Similarly, using the same method as in Section 3.3.3, the global weights of sub-factors can also be obtained as in Table 3.

\section{Fuzzy Comprehensive Evaluation}

Firstly, the petroleum enterprise's leader was formally informed that we were requesting assistance with administering this questionnaire survey. The leader assigned 10 administrative assistants to distribute the questionnaire to employees. Before all the employees were asked to filled out the questionnaire, they were provided with an introduction to human factors and safety behaviors since the purpose of this study is to assess and improve employees' safety behaviors and attitudes. Thus, the more common agree/disagree rating scale was used to survey employees-it adopts a five-point Likert scale to collect questionnaire data $(1=$ strongly disagree, $2=$ disagree, $3=$ neutral, $4=$ agree, and $5=$ strongly agree) [61].

Secondly, in the first survey, a total of 611 questionnaires were distributed to employees, yielding 532 valid questionnaires. According to the results of the questionnaire, employee operational behavior was observed and guided based on the application of the BBS approach in the oilfield enterprise. After a period of time, a second survey was issued. In the second survey, a total of 683 questionnaires were distributed to employees, yielding 631 valid questionnaires. Finally, the membership matrix was calculated based on the valid questionnaire data and Equations (19)-(21):

$$
\begin{aligned}
R A_{1} & =\left[\begin{array}{lllll}
0.0000 & 0.0018 & 0.0572 & 0.5572 & 0.3838 \\
0.0004 & 0.0000 & 0.0222 & 0.3021 & 0.6753 \\
0.0004 & 0.0000 & 0.0595 & 0.3241 & 0.6160 \\
0.0000 & 0.0000 & 0.0517 & 0.4425 & 0.5058
\end{array}\right] \\
R A_{2} & =\left[\begin{array}{lllll}
0.0000 & 0.0026 & 0.0634 & 0.4982 & 0.4357 \\
0.0000 & 0.0017 & 0.0543 & 0.4272 & 0.5168 \\
0.0000 & 0.0018 & 0.0580 & 0.5077 & 0.4326 \\
0.0000 & 0.0000 & 0.0320 & 0.4501 & 0.5179 \\
0.0000 & 0.0009 & 0.0230 & 0.4670 & 0.5092
\end{array}\right]
\end{aligned}
$$




$$
\begin{aligned}
& R A_{3}=\left[\begin{array}{lllll}
0.0018 & 0.0123 & 0.0608 & 0.4229 & 0.5022 \\
0.0000 & 0.0018 & 0.0877 & 0.5416 & 0.3689 \\
0.0014 & 0.0101 & 0.0990 & 0.5298 & 0.3598
\end{array}\right] \\
& R A_{4}=\left[\begin{array}{lllll}
0.0009 & 0.0018 & 0.1022 & 0.5893 & 0.2968 \\
0.0080 & 0.0066 & 0.1137 & 0.5091 & 0.3627 \\
0.0000 & 0.0009 & 0.0570 & 0.4408 & 0.5013
\end{array}\right] \\
& R A_{5}=\left[\begin{array}{lllll}
0.0014 & 0.0090 & 0.0976 & 0.4738 & 0.4182 \\
0.0004 & 0.0017 & 0.0808 & 0.3873 & 0.5297 \\
0.0004 & 0.0000 & 0.0544 & 0.3321 & 0.6131 \\
0.0004 & 0.0000 & 0.0594 & 0.4112 & 0.5290
\end{array}\right] \\
& R B_{1}=\left[\begin{array}{lllll}
0.0000 & 0.0000 & 0.0308 & 0.3805 & 0.5888 \\
0.0000 & 0.0000 & 0.0319 & 0.2428 & 0.7253 \\
0.0000 & 0.0000 & 0.0590 & 0.3562 & 0.5848 \\
0.0000 & 0.0000 & 0.0508 & 0.4138 & 0.5353
\end{array}\right] \\
& R B_{2}=\left[\begin{array}{lllll}
0.0067 & 0.0000 & 0.0759 & 0.3887 & 0.5287 \\
0.0007 & 0.0000 & 0.0431 & 0.4098 & 0.5464 \\
0.0004 & 0.0000 & 0.0394 & 0.4965 & 0.4637 \\
0.0043 & 0.0000 & 0.0475 & 0.3486 & 0.5996 \\
0.0007 & 0.0000 & 0.0188 & 0.3359 & 0.6446
\end{array}\right] \\
& R B_{3}=\left[\begin{array}{lllll}
0.0000 & 0.0007 & 0.1058 & 0.3481 & 0.5454 \\
0.0000 & 0.0000 & 0.1058 & 0.5019 & 0.3923 \\
0.0000 & 0.0023 & 0.1385 & 0.3527 & 0.5066
\end{array}\right] \\
& R B_{4}=\left[\begin{array}{lllll}
0.0000 & 0.0008 & 0.1499 & 0.4833 & 0.3660 \\
0.0000 & 0.0000 & 0.1457 & 0.5144 & 0.3399 \\
0.0004 & 0.0000 & 0.0957 & 0.3683 & 0.5356
\end{array}\right] \\
& R B_{5}=\left[\begin{array}{lllll}
0.0007 & 0.0000 & 0.0802 & 0.3987 & 0.5203 \\
0.0004 & 0.0015 & 0.0981 & 0.3616 & 0.5384 \\
0.0000 & 0.0000 & 0.0584 & 0.3968 & 0.5447 \\
0.0000 & 0.0000 & 0.0552 & 0.4943 & 0.4505
\end{array}\right]
\end{aligned}
$$

where $R A_{1-5}$ and $R B_{1-5}$ represent the membership matrices of the first and second evaluation, respectively. Taking the membership matrix $R A_{1}$ as an example, based on Table $2\left(N_{11}=0,2,43,314\right.$, 173) and Equations (19) and (20), $R A_{1}=(0.0000,0.0018,0.0572,0.5572,0.3838)$ with $\mathrm{p}_{i},(i=1,2, \ldots, 5)$. The membership matrices are calculated based on the two sets of survey data.

From the membership matrices obtained above, we can determine the first-layer FCE results for the two surveys. The first-layer FCE result is calculated according to each sub-factor weight $W_{i}$ and each corresponding membership matrix $R_{i}$ of the $U$ layer based on Equation (22):

$$
\begin{aligned}
S A_{1}=\omega_{U 1} \times R A_{1} & =(0.2248,0.2729,0.2768,0.2255) \times\left[\begin{array}{ccccc}
0.0000 & 0.0018 & 0.0572 & 0.5572 & 0.3838 \\
0.0004 & 0.0000 & 0.0222 & 0.3021 & 0.6753 \\
0.0004 & 0.0000 & 0.0595 & 0.3241 & 0.6160 \\
0.0000 & 0.0000 & 0.0517 & 0.4425 & 0.5058
\end{array}\right] \\
& =(0.0002,0.0004,0.0470,0.3972,0.5551) .
\end{aligned}
$$

Similar to the $S A_{1}$ calculation, the calculation results of other membership degrees can be obtained as shown in Table 4. 
Table 4. Calculation results of membership degree.

\begin{tabular}{cccccc}
\hline Index & Very High (5) & High (4) & Average (3) & Low (2) & Very Low (1) \\
\hline$S A_{1} / S B_{1}$ & $0.5551 / 0.6129$ & $0.3972 / 0.3437$ & $0.0470 / 0.0434$ & $0.0004 / 0.0000$ & $0.0002 / 0.0000$ \\
$S A_{2} / S B_{2}$ & $0.4841 / 0.5575$ & $0.4680 / 0.3942$ & $0.0466 / 0.0458$ & $0.0014 / 0.0000$ & $0.0000 / 0.0026$ \\
$S A_{3} / S B_{3}$ & $0.4161 / 0.4859$ & $0.4932 / 0.3969$ & $0.0811 / 0.1161$ & $0.0084 / 0.0010$ & $0.0011 / 0.0000$ \\
$S A_{4} / S B_{4}$ & $0.3909 / 0.4196$ & $0.5143 / 0.4511$ & $0.0893 / 0.1290$ & $0.0029 / 0.0003$ & $0.0027 / 0.0001$ \\
$S A_{5} / S B_{5}$ & $0.5217 / 0.5079$ & $0.4028 / 0.4196$ & $0.0722 / 0.0717$ & $0.0025 / 0.0003$ & $0.0006 / 0.0003$ \\
\hline
\end{tabular}

$S A_{1-5}$ and $S B_{1-5}$ represent the first-layer fuzzy comprehensive results of the first and second evaluations, respectively.

We constructed a fuzzy relationship matrix $R A$ and $R B$ from the $S A_{1-5}$ and $S B_{1-5}$ as follows:

$$
\begin{aligned}
R A & =\left[\begin{array}{lllll}
0.0002 & 0.0004 & 0.0470 & 0.3972 & 0.5551 \\
0.0000 & 0.0014 & 0.0466 & 0.4680 & 0.4841 \\
0.0011 & 0.0084 & 0.0811 & 0.4932 & 0.4161 \\
0.0027 & 0.0029 & 0.0893 & 0.5143 & 0.3909 \\
0.0006 & 0.0025 & 0.0722 & 0.4028 & 0.5217
\end{array}\right] \\
R B & =\left[\begin{array}{lllll}
0.0000 & 0.0000 & 0.0434 & 0.3437 & 0.6129 \\
0.0026 & 0.0000 & 0.0458 & 0.3942 & 0.5575 \\
0.0000 & 0.0010 & 0.1161 & 0.3969 & 0.4859 \\
0.0001 & 0.0003 & 0.1290 & 0.4511 & 0.4196 \\
0.0003 & 0.0003 & 0.0717 & 0.4196 & 0.5079
\end{array}\right]
\end{aligned}
$$

According to Equation (22) and the factors' weight values, the result of the second-layer comprehensive evaluation is as follows:

$$
\begin{aligned}
B_{1}=\omega_{i} \cdot R A & =(0.2261,0.1836,0.2066,0.1618,0.2219)\left[\begin{array}{lllll}
0.0002 & 0.0004 & 0.0470 & 0.3972 & 0.5551 \\
0.0026 & 0.0014 & 0.0466 & 0.4680 & 0.4841 \\
0.0011 & 0.0084 & 0.0811 & 0.4932 & 0.4161 \\
0.0027 & 0.0029 & 0.0893 & 0.5143 & 0.3909 \\
0.0006 & 0.0025 & 0.0722 & 0.4028 & 0.5217
\end{array}\right] \\
& =(0.0008,0.0031,0.0664,0.4502,0.4794)
\end{aligned}
$$

where $B_{1}$ and $B_{2}$ represent the FCE results of the first and second evaluations, respectively.

\section{Discussion and Analysis of the Results}

\subsection{Weight Analysis}

\subsubsection{Comparison Between the Weight of FAHP and AHP}

To further verify the reasonableness of the proposed FAHP, comparisons between the global weight values from the FAHP and AHP calculations are performed in Figure 2. The global weight is calculated by AHP, shown in red. In Figure 3, it is easy to see that the calculation results of AHP fluctuate greatly and reflect major differences. For example, the difference between $U_{12}$ and $U_{51}$ is 
0.2113. Therefore, the method not only produces great differences in weight distribution, but also has a strong subjective influence on experts' preferences. However, the global weight values calculated by FAHP are shown in blue. The calculation results of FAHP point to consistent weight distributions and small differences, such as $U_{31}(0.0777)$ and $U_{23}(0.0312)$ — the difference between them is 0.0465 . The results show that this method is less affected by the subjective preferences of experts.

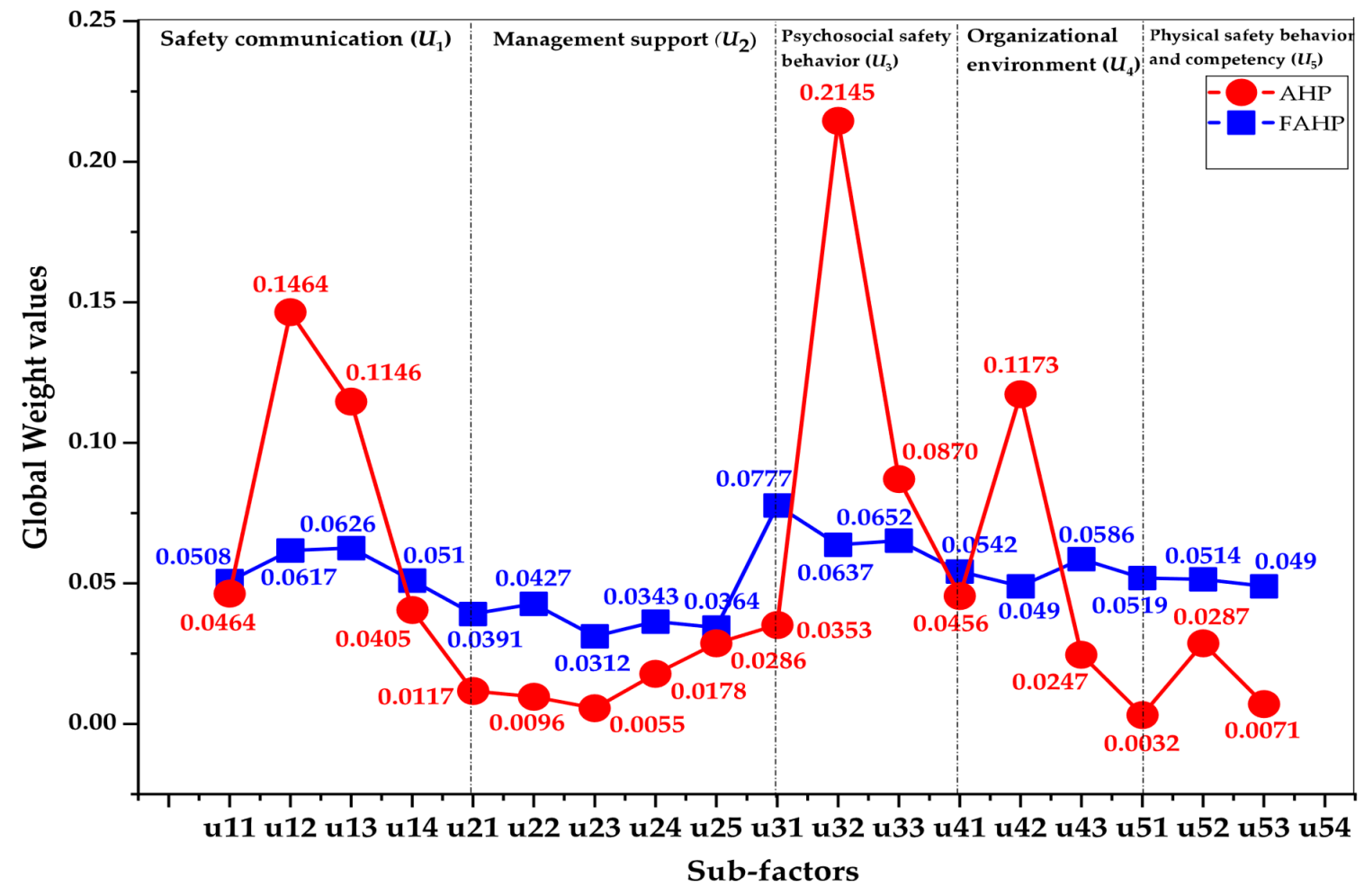

Figure 2. Global weights of the sub-factors.

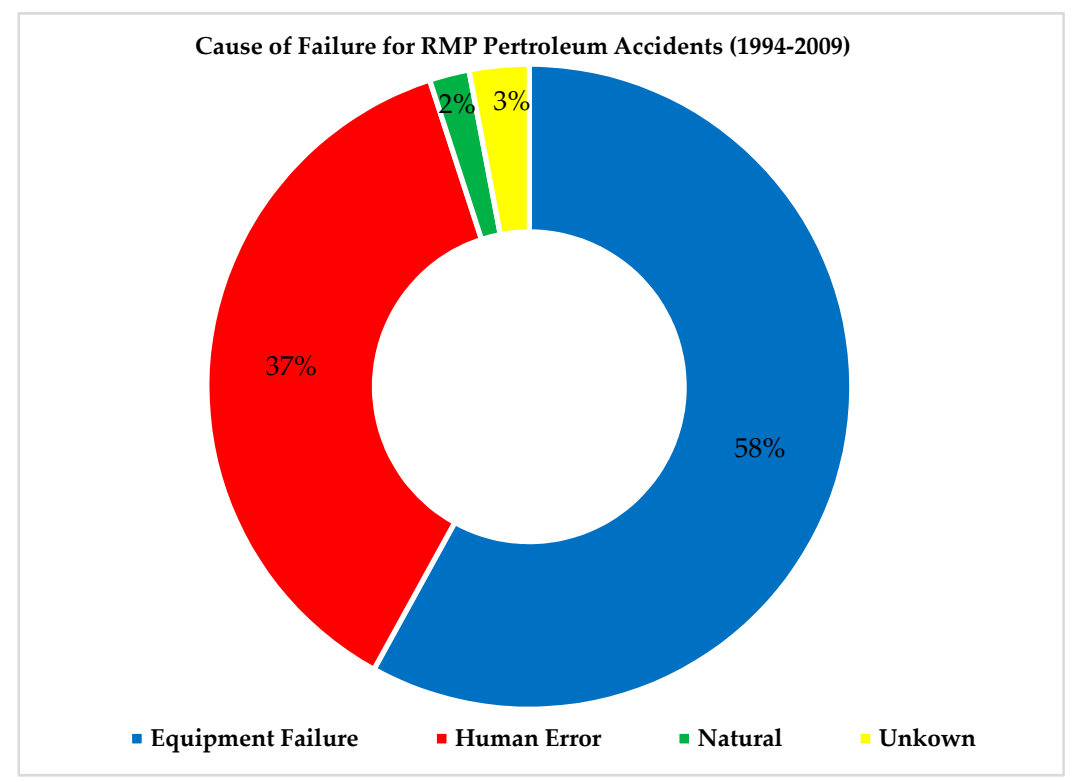

Figure 3. Different causes of failures leading to reported petroleum accidents. 


\subsubsection{Analysis of the Global Weights Based on FAHP}

As shown in Figure 2, personal attention at work $\left(U_{31}\right)$, corporate funding investment of safety production $\left(U_{54}\right)$, personal psychological quality $\left(U_{33}\right)$, and the performance of workers in daily safety production $\left(U_{32}\right)$ have the greatest impact. Conversely, corporate improvement of the degree of safety production plans $\left(U_{21}\right)$, corporate funding investment of safety production $\left(U_{24}\right)$, corporate supervision of safety production $\left(U_{25}\right)$, and corporate reward for, and punishment of safety production $\left(U_{23}\right)$ have less influence and are overlooked factors.

In Figure 2, we also rank the global weights of $\left(U_{\mathrm{ij}}\right)$ from large to small according to their values in Table 3. Based on the above analysis, it is clear that the main overlooked factors $\left(U_{4}\right)$ and sub-factors (especially $U_{24}, U_{25}$, and $U_{23}$ ) are potential risk factors. These may lead to occupational injuries and accidents in the petroleum enterprise. Thus, it is necessary to use the BBS approach to improve the overlooked factors.

\subsection{Comparing the Data of the Oil Industry and Human Assessment (FAHP)}

\subsubsection{Annual Accident and Occupational Injury Statistics Reported in RMP Databases}

Federal regulations demand that industrial enterprises file a Risk Management Plan with the United States Environmental Protection Agency [62]. The information is then stored in a national information system, called the Risk Management Program (RMP) database. The RMP database includes information on occupational injuries and accidents reported by the chemical and oil sectors of the processing industry. Furthermore, the information must report consequences such as injuries, evacuation, deaths, and property damage [63].

Consequently, driven by the motivation to reduce occupational injury and accidents in the oil industry, this paper uses the RMP databases to analyze accidents and their consequences. Based on the data from the RMP from 1994 to 2009, three waves of reported accidents were studied collectively in order to understand the accident profile.

Table 5 shows the proportion of accidents deriving from oil- and chemical-related processing versus the total petrochemical accidents in the RMP database. In general, oil accidents only account for about $28 \%$, and significant consequences, such as death, are equally prevalent in oil and chemical processing accidents. About $55 \%$ of accidents leading to mass evacuation and shelter in place are oil-related accidents.

Table 5. RMP database showing the percentage of oil and chemical incidents versus the total petrochemical accidents.

\begin{tabular}{cccccc}
\hline Consequence & Total & Petrochemical & Chemical & \%Petroleum & \%Chemical \\
\hline Accidents reported & 2528 & 707 & 1821 & 28 & 72 \\
Fatalities & 87 & 44 & 43 & 51 & 49 \\
Total Injuries & 2725 & 961 & 1764 & 35 & 65 \\
Hospitalization \& Treatment & 9475 & 1806 & 7669 & 19 & 81 \\
Evacuation \& Shelter in place & 563,015 & 308,561 & 254,454 & 55 & 45 \\
\hline
\end{tabular}

Table 5 also shows that the consequences of oil-related accidents are more severe than those of chemical accidents. As a result, oil refineries must take safety measures because, even if there are fewer accidents, their consequences will be worse.

\subsubsection{The Different Initiating Causes of Oil Accidents in the RMP Database}

Figure 3 shows the different causes leading to oil accidents in the RMP database. Equipment failures account for about $58 \%$ of total accidents, with human error resulting in about $37 \%$ of all oil-related accidents. Accidents that occur due to unknown and natural causes account for $3 \%$ and 
$2 \%$, respectively. Therefore, the major cause of accidents in the oil industry is equipment failure, followed by human error.

\subsubsection{The Data on Occupational Injuries and Accidents, Compared with Human Assessment}

Figure 3 shows the different causes leading to oil accidents, in which equipment failure caused by abrasion and product quality may be major. To some degree, this is inevitable. However, human error is completely avoidable. The oil industry can reduce the occurrence of human error by means of BBS, bottom-up safety communication, and improvement of the safety climate. In this paper, about $37 \%$ of the human factor is analyzed in detail and ranked to find the most important factors, so as to reduce the safety accidents caused by human error.

As shown in Figure 4, about $37 \%$ of the human factor is divided into five parts, including safety communication $\left(U_{1}\right)$, management support $\left(U_{2}\right)$, psychosocial safety behavior $\left(U_{3}\right)$, organizational environment $\left(U_{4}\right)$, and physical safety behavior and competency $\left(U_{5}\right)$. The weights of factors and sub-factors were obtained by using the FAHP method. Safety communication $\left(U_{1}\right)$ represents the highest influence on the safety performance among all five factors, followed by physical safety behavior and competency $\left(U_{5}\right)$, psychosocial safety behavior $\left(U_{3}\right)$, management support $\left(U_{2}\right)$, and organizational environment $\left(U_{4}\right)$. Thus, employees' psychological behavior $\left(U_{2}\right)$ and safety education $\left(U_{4}\right)$ are the overlooked factors that should be improved to achieve better safety performance.

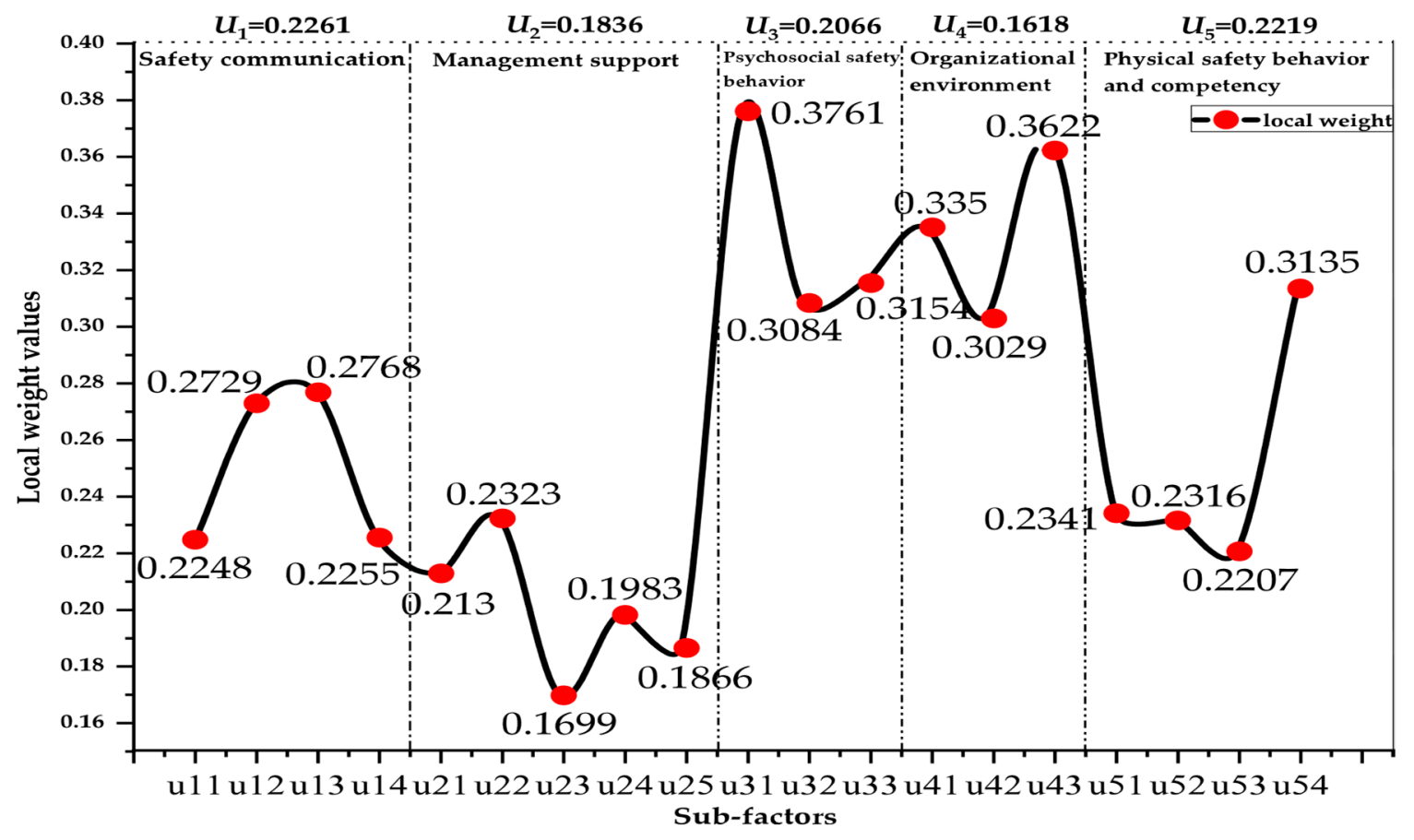

Figure 4. Local weights of the factors and sub-factors.

In conclusion, the weighted results are obtained after group discussions with experts, scholars, and managers, and the key human factors causing oil industry accidents are determined based on their weight ranking. Furthermore, the analysis of the weight values indeed provides reasonable, scientific guidance for the relevant leaders, operators, and managers. The approach can also be applied to the safety performance assessment of other industries and areas.

\subsection{Comprehensive Analysis of Results}

The results of the first FCE show that the probability of very high safety performance is 0.4580 , and the probabilities of high, average, low, and very low are 0.4601, 0.0775, 0.0026, and 0.0021, 
respectively. In line with the maximum membership degree principle, the FCE result for the safety performance is very high. The result of the second FCE shows that the probability of very high safety performance is 0.4836 , and the probabilities of high, average, low, and very low are $0.4523,0.0626$, 0.0010 , and 0.0008 , respectively. In line with the maximum membership degree principle, the FCE result for the safety performance is very high. Due to the final value of the second evaluation being higher than that of the first one, the second one is better. The compared FCE results are given in Figure 5.

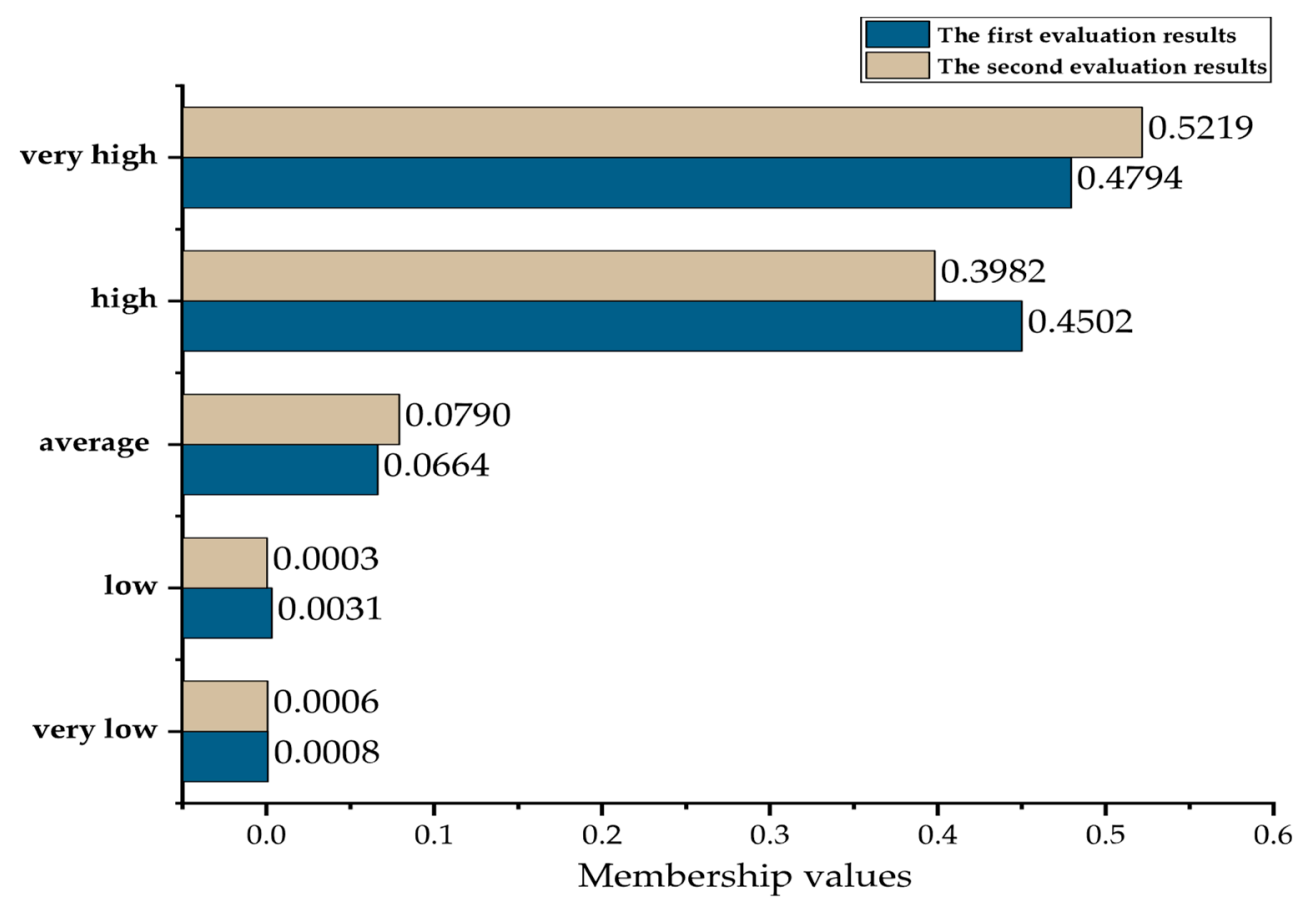

Figure 5. Line chart of the safety performance fuzzy evaluation.

Figure 5 shows that the safety performance of the second FCE is superior to that of the first assessment. In addition, the safety behaviors and psychology of the employees improved following bottom-up safety communication and BBS reinforcement. Meanwhile, the FCE results indicate the current safety performance level to help leaders and managers with preventing potential accidents. Safety performance postintervention levels were better than for the first FCE results. As a matter of fact, the numbers of occupational injuries and days away decreased.

\section{Conclusions}

In China, human factors are more common than equipment failure in oil industry accidents, but often lead to more serious consequences. Many employees have been killed in oil industry accidents over the past decade. In addition, hundreds of employees are dying of chronic occupational disease or are disabled for life. The purpose of this study was to establish a safety assessment model for petrochemical enterprises as well as to guide management in developing bottom-up safety communication with employees. According to the results of this study, the conclusions are as follows:

(1) The oil industry has made obvious progress in the field of environmental protection, safety management, and social responsibility in recent years. However, there is still much room for improvement in terms of sustainable safety development. Human factors are often defined as the root cause of incidents leading to oil accidents. The oil industry is becoming more employee-centered and must make efforts to improve safety performance.

(2) This study shows the importance of human factors to sustainable safety development in the oil industry. Based on the industry investigation and literature review, bottom-up safety 
communication would reduce the incidence of accidents in the oil industry. In conclusion, safety performance improvements are likely to be more efficient when employees are aware that their behaviors and psychology are also being observed and evaluated. Therefore, we can conclude that most oil accidents can be prevented by bottom-up safety communication, especially safety training of operators.

(3) This paper proposes a comprehensive safety performance assessment model based on human factors, FAHP, and FCE. Experts; knowledge and experience are systematically combined to determine the weight of factors and sub-factors based on FAHP. Weight ranking can also help leaders and managers with their safety strategy, reducing potential risk factors by implementing the BBS approach. Furthermore, the combined method can also be applied in the chemical and gas industry.

\section{Limitations of the Method}

Owing to research limitations, the assessment model cannot include all categories of human factors. Second, there is a lack of a standardized database system to analyze and assess the obtained behavior data. Thus, incorrect data may be entered or summarized. Finally, if the safety communication and behavioral interventions are removed, the effects of the existing BBS approach will be unsustainable. As a result, it is our sincere hope that future researchers will develop human factors and other behavioral science approaches to improve sustainable development and the safety performance in the oil industry.

Author Contributions: Methodology, X.C. and J.Z.; Writing—original draft preparation, J.Z.; Writing-review and editing, X.C. and J.Z.; Software, J.Z.; Conceptualization, X.C. and Q.S.; Investigation, X.C. and Q.S.

Funding: This research was funded by the National Science Fund of China, grant number 71571091, 71771112.

Conflicts of Interest: The authors declare no conflict of interest.

\section{References}

1. Ratnayake, R.M.C.; Chaudry, O. Maintaining sustainable performance in operating petroleum assets via a lean-six-sigma approach. Int. J. Lean Six Sigma 2017, 8, 33-52. [CrossRef]

2. Ahmad, W.; Rezaei, J.; Tavasszy, L.A.; de Brito, M.P. Commitment to and preparedness for sustainable supply chain management in the oil and gas industry. J. Environ. Manag. 2016, 180, 202-213. [CrossRef] [PubMed]

3. Edokpolo, B.; Yu, Q.J.; Connell, D. Health Risk Assessment for Exposure to Benzene in Petroleum Refinery Environments. Int. J. Environ. Res. Public Health 2015, 12, 595-610. [CrossRef] [PubMed]

4. Johnson, C.; Holloway, C.M. A survey of logic formalisms to support mishap analysis. Reliab. Eng. Syst. Saf. 2003, 80, 271-291. [CrossRef]

5. Dahl, Ø. Safety compliance in a highly regulated environment: A case study of workers' knowledge of rules and procedures within the petroleum industry. Saf. Sci. 2013, 60, 185-195. [CrossRef]

6. Kariuki, S.G.; Löwe, K. Integrating human factors into process hazard analysis. Reliab. Eng. Syst. Saf. 2007, 92, 1764-1773. [CrossRef]

7. Manca, D.; Brambilla, S. Dynamic simulation of the BP Texas City refinery accident. J. Loss Prev. Process Ind. 2012, 25, 950-957. [CrossRef]

8. Kalantarnia, M.; Khan, F.; Hawboldt, K. Modelling of BP Texas City refinery accident using dynamic risk assessment approach. Process Saf. Environ. Prot. 2010, 88, 191-199. [CrossRef]

9. Singh, B.; Jukes, P.; Poblete, B.; Wittkower, B. 20 years on lessons learned from Piper Alpha. The evolution of concurrent and inherently safe design. J. Loss Prev. Process Ind. 2010, 23, 936-953. [CrossRef]

10. Heimann, L. Repeated Failures in the Management of High Risk Technologies. Eur. Manag. J. 2005, 23, 105-117. [CrossRef]

11. Bea, R.G. Human and organization factors: Engineering operating safety into offshore structures. Reliab. Eng. Syst. Saf. 1998, 61, 109-126. [CrossRef]

12. Pate-Cornell, M.E. Learning from the Piper Alpha Accident: A Postmortem Analysis of Technical and Organizational Factors. Risk Anal. 1993, 13, 215-232. [CrossRef]

13. Urbina, I. In Gulf, it was unclear who was in charge of rig. The New York Times, 5 June 2010; p. A1. 
14. Bettina, S.; Hochman, M.G. Improving Safety through Human Factors Engineering. Radiogr. Rev. Publ. Radiol. Soc. N. Am. Inc. 2015, 35, 1694-1705. [CrossRef]

15. Norton, T.A.; Zacher, H.; Parker, S.L.; Ashkanasy, N.M. Bridging the Gap between Green Behavioral Intentions and Employee Green Behavior: The Role of Green Psychological Climate. J. Organ. Behav. 2017, 38, 996-1015. [CrossRef]

16. Sulzer-Azaroff, B.; Austin, J. Does BBS work? Behavior-based safety and injury reduction: A survey of the evidence. Prof. Saf. 2000, 45, 19-24.

17. Lipscomb, H.J.; Schoenfisch, A.L.; Wilfrid, C. Non-reporting of work injuries and aspects of jobsite safety climate and behavioral-based safety elements among carpenters in Washington State. Am. J. Ind. Med. 2015, 58, 411-421. [CrossRef]

18. Avinash, K.; Barbara, O.; Barbara, P. Reducing hospital ICU noise: A behavior-based approach. J. Healthc. Eng. 2015, 5, 229-246. [CrossRef]

19. Shirmohammadi, H.; Hadadi, F.; Saeedian, M. Clustering Analysis of Drivers Based on Behavioral Characteristics Regarding Road Safety. Int. J. Civ. Eng. 2019, 17, 1327-1340. [CrossRef]

20. Wang, X.; Xing, Y.; Luo, L.; Yu, R. Evaluating the effectiveness of Behavior-Based Safety education methods for commercial vehicle drivers. Accid. Anal. Prev. 2018, 117, 114-120. [CrossRef]

21. Ventikos, N.P.; Lykos, G.V.; Padouva, I.I. How to achieve an effective behavioral-based safety plan: The analysis of an attitude questionnaire for the maritime industry. J. Marit. Aff. 2014, 13, 207-230. [CrossRef]

22. Cooper, M.D. Exploratory Analyses of the Effects of Managerial Support and Feedback Consequences on Behavioral Safety Maintenance. J. Organ. Behav. Manag. 2006, 26, 1-41. [CrossRef]

23. Fargnoli, M.; Lombardi, M. Preliminary Human Safety Assessment (PHSA) for the Improvement of the Behavioral Aspects of Safety Climate in the Construction Industry. Buildings 2019, 9, 69. [CrossRef]

24. Zhang, P.; Li, N.; Fang, D.; Wu, H. Supervisor-Focused Behavior-Based Safety Method for the Construction Industry: Case Study in Hong Kong. J. Constr. Eng. Manag. 2017, 143, 05017009. [CrossRef]

25. Choudhry, R.M. Behavior-based safety on construction sites: A case study. Accid. Anal. Prev. 2014, 70, 14-23. [CrossRef] [PubMed]

26. Depasquale, J.P.; Geller, E.S. Critical Success Factors for Behavior-Based Safety: A Study of Twenty Industry-wide Applications. J. Saf. Res. 1999, 30, 237-249. [CrossRef]

27. Cheng, Y.H. Railway safety climate: A study on organizational development. Int. J. Occup. Saf. Ergon. 2017, 1-37. [CrossRef] [PubMed]

28. Cambridge Center for Behavioral Studies, Commission on Behavioral Applications. Companies Achieving Behavioral Safety Accreditation. 2010. Available online: http://www.behavior.org/resource.php?id=327 (accessed on 25 June 2018).

29. Rodriguez, M.A.; Bell, J.; Brown, M.; Carter, D. Integrating Behavioral Science with Human Factors to Address Process Safety. J. Organ. Behav. Manag. 2017, 37, 301-315. [CrossRef]

30. Kubler, S.; Robert, J.; Derigent, W.; Voisin, A. A state-of the-art survey \& testbed of fuzzy AHP (FAHP) applications. Expert Syst. Appl. 2016, 65, 398-422. [CrossRef]

31. Saaty, T.L. A scaling method for priorities in hierarchical structures. J. Math. Psychol. 1977, 15, $234-281$. [CrossRef]

32. Saaty, T.L. How to make a decision: The analytic hierarchy process. Eur. J. Oper. Res. 1994, $24,19-43$. [CrossRef]

33. Chen, K.; Khan, F.; Jing, X. Safety Assessment of Natural Gas Purification Plant. Process Saf. Environ. Prot. 2017, 113, 459-466. [CrossRef]

34. Raviv, G.; Shapira, A.; Fishbain, B. AHP-based analysis of the risk potential of safety incidents: Case study of cranes in the construction industry. Saf. Sci. 2017, 91, 298-309. [CrossRef]

35. Nouri, J.; Azadeh, A.; Fam, I.M. The evaluation of safety behaviors in a gas treatment company in Iran. J. Loss Prev. Process Ind. 2008, 21, 319-325. [CrossRef]

36. Ayağ, Z.; Özdemir, R.G. A Fuzzy AHP Approach to Evaluating Machine Tool Alternatives. J. Intell. Manuf. 2006, 17, 179-190. [CrossRef]

37. Li, W.; Yu, S.; Pei, H.; Zhao, C.; Tian, B. A hybrid approach based on fuzzy AHP and 2-tuple fuzzy linguistic method for evaluation in-flight service quality. J. Air Transp. Manag. 2017, 60, 49-64. [CrossRef]

38. Choudhary, D.; Shankar, R. An STEEP-fuzzy AHP-TOPSIS framework for evaluation and selection of thermal power plant location: A case study from India. Energy 2012, 42, 510-521. [CrossRef] 
39. Alipour, M.; Alighaleh, S.; Hafezi, R.; Omranievardi, M. A new hybrid decision framework for prioritizing funding allocation to Iran's energy sector. Energy 2017, 121, 388-402. [CrossRef]

40. Celik, E.; Akyuz, E. An interval type-2 fuzzy AHP and TOPSIS methods for decision-making problems in maritime transportation engineering: The case of ship loader. Ocean Eng. 2018, 155, 371-381. [CrossRef]

41. An, T.N.; Long, D.N.; Long, L.H.; Dang, C.N. Quantifying the complexity of transportation projects using the fuzzy analytic hierarchy process. Int. J. Proj. Manag. 2015, 33, 1364-1376. [CrossRef]

42. Bozanic, D.; Tešić, D.; Milićević, J. A hybrid fuzzy AHP-MABAC model: Application in the Serbian Army-The selection of the location for deep wading as a technique of crossing the river by tanks. Decis. Mak. Appl. Manag. Eng. 2018, 1, 143-164. [CrossRef]

43. Shaygan, A.; Testik, Ö.M. A fuzzy AHP-based methodology for project prioritization and selection. Soft Comput. 2017, 23, 1309-1319. [CrossRef]

44. Singh, A.; Prasher, A. Measuring healthcare service quality from patients' perspective: Using Fuzzy AHP application. Total Qual. Manag. Bus. Excell. 2017, 30, 284-300. [CrossRef]

45. Singh, R.K.; Gunasekaran, A.; Kumar, P. Third party logistics (3PL) selection for cold chain management: A fuzzy AHP and fuzzy TOPSIS approach. Ann. Oper. Res. 2018, 267, 531-553. [CrossRef]

46. Samanlioglu, F.; Taskaya, Y.E.; Gulen, U.C.; Cokcan, O. A Fuzzy AHP-TOPSIS-Based Group Decision-Making Approach to IT Personnel Selection. Int. J. Fuzzy Syst. 2018, 20, 1576-1591. [CrossRef]

47. Demirel, T.; Demirel, N.Ç.; Kahraman, C. Fuzzy analytic hierarchy process and its application. In Fuzzy Multi-Criteria Decision Making; Springer: Boston, MA, USA, 2008; pp. 53-83.

48. Van Laarhoven, P.J.M.; Pedrycz, W. A fuzzy extension of Saaty's priority theory. Fuzzy Sets Syst. 1983, 11, 199-227. [CrossRef]

49. Huang, S.H.S.; Hsu, W.K.K. Evaluating the service requirements of combination air cargo carriers. Asia Pac. Manag. Rev. 2015, 17, 109-112. [CrossRef]

50. Buckley, J.J. Fuzzy hierarchical analysis. Fuzzy Sets Syst. 1985, 17, 233-247. [CrossRef]

51. Chang, D.Y. Applications of the extent analysis method on fuzzy AHP. Eur. J. Oper. Res. 1996, 95, 649-655. [CrossRef]

52. Kaufmann, A.; Gupta, M.M. Introduction to Fuzzy Arithmetic: Theory and Applications. Math. Comput. 1986, 47, 762-763. [CrossRef]

53. Yager, R.R. A procedure for ordering fuzzy subsets of the unit interval. Inf. Sci. 1981, 24, 143-161. [CrossRef]

54. Zohar, D. Safety climate in industrial organizations: Theoretical and applied implications. J. Appl. Psychol. 1980, 65, 96-102. [CrossRef]

55. Wills, A.R.; Biggs, H.C.; Watson, B.C. Analysis of a Safety Climate Measure for Occupational Vehicle Drivers and Implications for Safer Workplaces. Aust. J. Rehabil. Couns. 2005, 11, 8-21. [CrossRef]

56. Cooper, M.D.; Phillips, R.A. Exploratory analysis of the safety climate and safety behavior relationship. J. Saf. Res. 2004, 35, 497-512. [CrossRef] [PubMed]

57. Lu, C.S.; Shang, K. An empirical investigation of safety climate in container terminal operators. J. Saf. Res. 2005, 36, 297-308. [CrossRef] [PubMed]

58. Asilian-Mahabadi, H.; Khosravi, Y.; Hassanzadeh-Rangi, N.; Hajizadeh, E.; Behzadan, A.H. Factors affecting unsafe behavior in construction projects: Development and validation of a new questionnaire. Int. J. Occup. Saf. Ergon. 2018, 1-8. [CrossRef] [PubMed]

59. Clarke, S. Perceptions of organizational safety: Implications for the development of safety culture. J. Organ. Behav. Int. J. Ind. Occup. Organ. Psychol. Behav. 1999, 20, 185-198. [CrossRef]

60. Cormier, B. Size of organisation, attitudes to work and job satisfaction. Ind. Relat. J. 2010, 14, 28-40. [CrossRef]

61. Likert, R. A technique for the measurement of attitudes. Arch. Psychol. 1932.

62. Environmental Protection Agency. Clean Air Act Section 112(r): Accidental Release Prevention/Risk Management Plan Rule (No. EPA 550-R-09e002); Office of Solid Waste and Emergency Response: Washington, DC, USA, 2009.

63. Elliott, M.R.; Kleindorfer, P.R.; Dubois, J.J.; Wang, Y.; Rosenthal, I. Linking OII and RMP data: Does everyday safety prevent catastrophic loss? Int. J. Risk Assess. Manag. 2008, 10, 130-146. [CrossRef]

(C) 2019 by the authors. Licensee MDPI, Basel, Switzerland. This article is an open access article distributed under the terms and conditions of the Creative Commons Attribution (CC BY) license (http://creativecommons.org/licenses/by/4.0/). 